\title{
Program Pemberdayaan dan Pengembangan Kewirausahaan Pondok Pesantren Mahasiswa Ma'arif NU Kota Metro Melalui Karya Seni Kaligrafi
}

\author{
Program for Empowerment and Entrepreneurship Development of Ma'arif NU Islamic Boarding \\ Schools in Metro City Through Calligraphy Artwork
}

\begin{tabular}{|c|}
\hline Hanif Amrulloh ${ }^{\text {1* }}$ \\
\hline Rizky Hidayatullah ${ }^{2}$ \\
\hline Agus Setiawan ${ }^{3}$ \\
\hline Ahmad Zarnuji 1 \\
\hline Dedi Setiawan ${ }^{4}$ \\
\hline Jaenullah 4 \\
\hline $\begin{array}{l}\text { 1Madrasah Ibtidaiyah Teacher } \\
\text { Education Study Program, Institut } \\
\text { Agama Islam Ma'arif NU Metro } \\
\text { Lampung, Metro, Lampung, } \\
\text { Indonesia }\end{array}$ \\
\hline $\begin{array}{l}\text { English Language Study Program, } \\
\text { Institut Agama Islam Ma'arif NU } \\
\text { Metro Lampung, Metro, Lampung, } \\
\text { Indonesia }\end{array}$ \\
\hline $\begin{array}{l}{ }^{3} \text { Ahwal As Syakhsiyah Study } \\
\text { Program, Institut Agama Islam } \\
\text { Ma'arif NU Metro Lampung, Metro, } \\
\text { Lampung, Indonesia }\end{array}$ \\
\hline $\begin{array}{l}\text { }{ }^{4} \text { Master of Islamic Education Study } \\
\text { Program, Institut Agama Islam } \\
\text { Ma'arif NU Metro Lampung, Metro, } \\
\text { Lampung, Indonesia }\end{array}$ \\
\hline $\begin{array}{l}\text { email: amrulloh.hanif@ } \\
\text { iaimnumetrolampung.ac.id }\end{array}$ \\
\hline $\begin{array}{l}\text { Kata Kunci } \\
\text { Kewirausahaan } \\
\text { Ma'arif NU } \\
\text { Pemberdayaan santri } \\
\text { Seni kaligrafi }\end{array}$ \\
\hline $\begin{array}{l}\text { Keywords: } \\
\text { Entrepreneurship } \\
\text { Ma'arif NU } \\
\text { Santri empowerment } \\
\text { Calligraphy art }\end{array}$ \\
\hline $\begin{array}{l}\text { Received: April } 2021 \\
\text { Accepted: September } 2021 \\
\text { Published: January } 2022\end{array}$ \\
\hline
\end{tabular}

\begin{abstract}
Abstrak
Pondok pesantren mahasiswa adalah Lembaga Pendidikan islam dengan sistem asrama di mana santrinya pendapat pendidikan agama islam dari pondok pesantren dan Pendidikan umum di perguruan tinggi. Pondok pesantren mahasiswa Institut Agama Islam Ma'arif NU (IAIMNU) Kota Metro adalah pondok pesantren di bawah Lembaga Pendidikan Ma'arif NU Kota Metro Lampung. Hingga saat ini pondok pesantren mahasiswa Ma'arif NU Kota Metro memiliki santriwan dan santriwati sekitar 70 orang. Berdasarkan potensi ini, terdapat peluang untuk pengembangan dalam keterampilan kewirausahaan. Para santri tidak semata memperkuat dalam bidang pendidikan umum dan keilmuan agama islam, melainkan keterampilan lain yang dibutuhkan salah satunya kewirausahaan. Ketrampilan yang di ajarkan salah satunya pembuatan seni kaligrafi yan juga memiliki potensi ekonomi yang sangat besar. Tujuan program ini antara lain memperkenalkan kewirausahaan kepada santri mahasiswa, mempraktikkan cara pembuatan seni kaligrafi dengan teknik prada dan mengaplikasikan pembuatan seni kaligrafi sebagai wirausaha. Pendampingan yang dilakukan menggunakan pendekatan ABCD. Pendampingan dalam pendekatan ini mengutamakan pemanfaatan potensi dan aset yang telah masyarakat miliki. Pendekatan ini, modal utama masyarakat dalam mencapai perubahan adalah kemampuan atau potensi. Hasil pendampingan menunjukkan santri terus melakukan pengembangan usaha kaligrafi yang dijalankan dengan keuntungan sepenuhnya untuk membiayai kebutuhan santri di pondok pesantren. Dari keuntungan tersebut, santri sudah tidak sepenuhnya bergantung dengan kiriman orang tua, hasil usaha kaligrafi yang dilakukan mampu memenuhi kebutuhan sendiri para santri yang berwirausaha.
\end{abstract}

\begin{abstract}
Islamic boarding schools for students are Islamic educational institutions with a boarding system in which students from Islamic boarding schools have Islamic religious education and general knowledge from universities. The Islamic Student Boarding School of the Ma'arif NU Islamic Institute in Metro City is located in Metro, Lampung. So far, there are approximately 70 students at the Ma'arif NU student boarding school in Metro City. There are prospects for advancement in entrepreneurial skills centered on this opportunity. To improve students in general education and Islamic scholarship, but with other skills currently needed, one of which is entrepreneurship. Making calligraphy art with tremendous economic potential is one of the skills taught in Islamic boarding schools. The goals of this program include introducing entrepreneurship to student students, learning how to use Prada techniques to create calligraphy art, and applying calligraphy artmaking as an entrepreneur. The ABCD method was used for the assistance given to Metro City Ma'arif NU Islamic boarding school students. In this strategy, service prioritizes using capacity and assets that the group already has. In this approach, the capacity or potential is the direct assistance of society in achieving progress. The assistance results showed that the students managed to develop a calligraphy company that was run at an entire profit to fund the needs of the Islamic boarding school students. Students are not solely dependent on parental submissions based on these benefits. The outcomes of the calligraphy efforts carried out will fulfill the needs of entrepreneurial learners.
\end{abstract}




\section{PENDAHULUAN}

Sumber daya manusia (SDM) menjadi salah satu faktor yang tidak bisa dipisahkan dengan sebuah organisasi, perusahaan juga institusi, baik pemerintahan maupun swasta. Sumber daya manusia juga merupakan kunci yang menentukan perkembangan Negara (Nuryanta, 2008; Tursunbayeva, 2019; Bilan et al., 2020). Salah satu pengembangan SDM yaitu pengembangan Pondok pesantren (pesantren) karena salah satu Lembaga Pendidikan agama Islam yang tertua di Indonesia (Syafe'i, 2017; Amrulloh \& Mahmudah, 2020). Pesantren memiliki potensi yang besar dalam pengembangannya baik dari segi pendidikan, sosial, ekonomi, maupun politik. Hal ini didasarkan pada keunggulan utama yang dimiliki oleh pesantren yakni sumber daya manusia (Haromain, 2013; Dellyana \& Sudrajad, 2021). Potensi pesantren dalam segi pengembangan ekonomi diutarakan oleh Gubernur Bank Indonesia Perry Warjiyo dikutip dari Ruang Media Bank Indonesia yang menyatakan bahwa pesantren memiliki potensi besar sebagai basis arus ekonomi Indonesia dengan tiga program kemandirian ekonomi. Pertama, pengembangan berbagai unit usaha berpotensi untuk memanfaatkan kerja sama antar pondok pesantren. Kedua, mendorong terjalinnya kerja sama antar pondok pesantren melalui virtual market. Ketiga, pengembangan holding pesantren. Melalui program pengembangan kemandirian pesantren diharapkan dapat mendorong pesantren sebagai penggerak perekonomian (Fatimah \& Suib, 2019).

Kaligrafi adalah tulisan indah yang dibuat dengan menggunakan prinsip penyusunan tertentu. Hal pokok dalam kaligrafi adalah tulisan yang indah mencakup tulisan dalam bahasa apa pun, baik zaman sekarang atau zaman dahulu. Berkaitan dengan penelitian ini, kaligrafi yang dimaksud adalah kaligrafi huruf arab. Israr menyebutkan macam-macam bentuk tulisan huruf arab/khoth yaitu khoth kufi, khoth tsulus, khoth naskhi, khoth farisi, khoth riq'ah, khoth diwani, dan khoth diwani jaly (Osborn, 2015; Graves et al., 2019). Jenis-jenis khoth yang disebutkan di atas adalah jenis-jenis khoth yang mengikuti kaidah atau aturan, seperti harus ditulis dengan menggunakan alat tulis yang berukuran tertentu atau harus diberi harakat atau tidak. Seni kaligrafi Islam Nusantara, selain pada makam atau nisan, juga terdapat pada media lain seperti deluang, kertas, lontar, kayu, logam, kaca dan bahan lainnya (Sholikhan et al., 2019).

Karya seni kaligrafi memiliki potensi ekonomi yang sangat besar. Selain berfungsi sebagai salah satu media dalam penyebaran agama Islam baik di Indonesia maupun di seluruh dunia, kaligrafi juga merupakan suatu karya seni rupa yang memiliki nilai seni dan ekonomi yang tinggi. Berdasarkan buku "Pengabdian Masyarakat Berbasis Riset: Pemanfaatan Sekam Padi Menjadi Kertas Sebagai Media Kaligrafi", terdapat potensi dan hal yang menarik yaitu karya seni kaligrafi yang dihasilkan menggunakan teknik prada. Karya seni ini memiliki tulisan yang timbul dengan warna yang menyerupai seperti warna logam emas dan perak. Berdasarkan karakteristik karya seni yang dihasilkan, kaligrafi yang dihasilkan dengan teknik ini memiliki potensi ekonomi yang sangat besar karna sangat unik dan menarik (Zarnuji et al., 2018).

Perkembangan pondok pesantren dalam segi pendidikan saat ini terlihat dari banyak munculnya pondok pesantren mahasiswa. Pondok pesantren mahasiswa adalah Lembaga Pendidikan Islam dengan sistem asrama di mana santrinya pendapat Pendidikan Islam dari pondok pesantren yang diasuh kiai dan Pendidikan umum dari perguruan tinggi (Ma`arif, 2019). Pondok Pesantren Mahasiswa Ma'arif NU kota Metro adalah pondok pesantren di bawah Lembaga Pendidikan Ma'arif NU Kota Metro yang berada di lingkungan Institut Agama Islam Ma'arif NU (IAIMNU) Metro Lampung. Hingga saat ini Pondok Pesantren Mahasiswa Ma'arif NU Kota Metro memiliki santriwan dan santriwati 70 orang. Selain potensi jumlah santri, Pondok Pesantren Ma'arif NU Kota Metro memiliki potensi dari segi keahlian santri dalam menghasilkan karya seni kaligrafi. Banyak santriwan dan santriwati di Pondok Pesantren Ma'arif NU Kota Metro yang menjadi juara dalam berbagai perlombaan seni kaligrafi. Berdasarkan potensi ini, dapat dilakukan pengembangan dalam bidang Pendidikan keterampilan. Dengan maksud bahwa, para santri tidak semata memperkuat dirinya dalam bidang Pendidikan umum dan keilmuan agama Islam, melainkan keterampilan lain yang saat ini dibutuhkan salah satunya kewirausahaan. Tujuan dilakukan pendampingan ini antara lain memperkenalkan kewirausahaan kepada santri, mempraktikkan cara pembuatan karya seni kaligrafi dengan teknik prada, dan mengaplikasikan pembuatan karya seni kaligrafi sebagai salah satu wirausaha. 


\section{METODE}

Pendampingan yang dilakukan pada santri Pondok Pesantren Mahasiswa Ma'arif NU Kota Metro menggunakan pendekatan Asset Based Community Development (ABCD). Pendampingan dalam pendekatan ini mengutamakan pemanfaatan potensi dan aset yang telah masyarakat miliki. Pendekatan ini, modal utama masyarakat dalam mencapai perubahan adalah kemampuan atau potensi.

Berikut adalah langkah-langkah pendampingan dalam proses pendekatan metode $\mathrm{ABCD}$ dan alat dalam menemukan dan mengenali aset adalah sebagai berikut:

1. Penemuan Apresiatif

Apresiasi dalam mendengarkan cerita sukses yang pernah diraih dan menghargai kemampuan yang dimiliki komunitas. Asumsi dalam penemuan apresiatif adalah setiap organisasi memiliki aset yang menjadikan komunitas hidup dan dapat berjalan dengan baik. Tahap selanjutnya adalah proses yang mendorong perubahan positif dengan fokus yang merujuk pada pengalaman dan kesuksesan yang terjadi di masa lalu. Appreciative Inquiry adalah cara yang positif untuk melakukan perubahan organisasi berdasarkan asumsi yang sederhana.

2. Analisis pengembangan aset

Pada tahapan ini, setelah komunitas mengenali potensi yang dimiliki selanjutnya adalah bagaimana mereka bisa melakukan impian yang telah dirumuskan pada tahap Focus Group Discussion (FGD). Untuk mengembangkan potensi kewirausahaan, masyarakat telah merangkai mimpi yaitu membuat kelompok usaha dengan produk karya seni kaligrafi. Dari mimpi tersebut, pada forum FGD diperoleh sebuah persetujuan bahwa dalam pengabdian ini hanya berfokus pada pengembangan dan penguatan kapasitas dalam kewirausahaan melalui pembuatan karya seni kaligrafi serta pendampingan pemasaran produk yang dihasilkan.

3. Analisis strategi program

Langkah awal yang peneliti lakukan adalah mengenal lebih dekat dan memperoleh kepercayaan dari kelompok dampingan agar proses pendampingan memperoleh kepercayaan dari masyarakat dan berjalan lancar sesuai rencana. Setelah mendapat kepercayaan, proses selanjutnya adalah mengadakan forum FGD. Pada proses FGD peneliti merumuskan strategi program, mengumpulkan informasi, kemudian merancang proses kewirausahaan, setelah itu mencari informasi untuk merumuskan strategi program dengan pelatihan pembuatan karya seni kaligrafi bersama para santri Pondok Pesantren Mahasiswa Ma'arif NU Kota Metro. Tahap terakhir adalah mengimplementasikan berbagai hal yang sudah dirumuskan pada tahap FGD.

4. Ringkasan narasi program

Pada tahapan aksi program, peneliti membuat rancangan yang telah disepakati bersama para santri Pondok Pesantren Mahasiswa Ma'arif NU Kota Metro pada tahap FGD yaitu membuat pelatihan pembuatan karya seni kaligrafi dengan teknik prada. Pada tahapan FGD telah dirumuskan bahwa pelatihan akan dilaksanakan pada tahap aksi yang telah disetujui bersama oleh santri Pondok Pesantren Mahasiswa Ma'arif NU Kota Metro. Peneliti berharap, bahwa dengan adanya pelatihan pembuatan karya seni kaligrafi dapat dimanfaatkan sebagai langkah awal dalam memulai wirausaha dan bisa meningkatkan kreativitas yang dimiliki oleh para santri Pondok Pesantren Mahasiswa Ma'arif NU Kota Metro. Diharapkan pula dapat memberdayakan para santri serta dapat meningkatkan dan menumbuhkan jiwa wirausaha pada santri Pondok Pesantren Mahasiswa Ma'arif NU Kota Metro.

5. Teknik monitoring dan evaluasi program

Untuk mengetahui tingkat keberhasilan pengembangan masyarakat berbasis aset yang berorientasi pada perubahan kelompok dampingan maka perlu adanya monitoring dan evaluasi. Proses monitoring dilakukan oleh peneliti dalam upaya untuk memaksimalkan proses pendampingan. Proses monitoring akan terus dilakukan oleh peneliti agar proses santri Pondok Pesantren Mahasiswa Ma'arif NU Kota Metro terus berkelanjutan.

Evaluasi dalam $A B C D$ adalah evaluasi apresiatif yaitu mengevaluasi bagaimana sumber daya dalam komunitas digunakan dan aset tambahan yang dapat dimobilisasi dengan efektif. $\mathrm{ABCD}$ mempelajari kapasitas dalam komunitas 
untuk memimpin secara mandiri atau meningkatkan partisipasi masyarakat dalam pembangunan. Evaluasi apresiatif mengajukan pertanyaan "seberapa jauh kegiatan yang dilaksanakan para santri Pondok Pesantren Mahasiswa Ma'arif NU Kota Metro dalam memulai usaha untuk meningkatkan kemandirian dan pendapatan?” (Zarnuji dkk., 2019).

\section{HASIL DAN PEMBAHASAN}

1. Penemuan Apresiatif

Dalam hal ini pendamping mencoba mewawancara salah satu pengurus Pondok Pesantren Ma'arif Metro yaitu saudara Qosim yang bercerita bahwa pernah mengalami kesuksesan dalam hal pengembangan Kewirausahaan ketika menjadi mahasiswa yaitu berwirausaha Reseller air isi ulang yang cukup menghasilkan, dan beliau berkeinginan untuk membuat suatu wirausaha yang dapat dikembangkan sebagai seorang santri dan dilakukan secara kolektif dengan para santri Ma'arif.

2. Analisis pengembangan aset

Dari hasil wawancara dan observasi para santri. Tim Melakukan FGD dengan tim dosen untuk menentukan kegiatan apa yang dapat dilakukan dalam pendampingan yaitu melakukan workshop kapasitas kewirausahaan dan juga pelatihan seni kaligrafi yang diharapkan dapat memperdayakan para santri Ma'arif Metro.

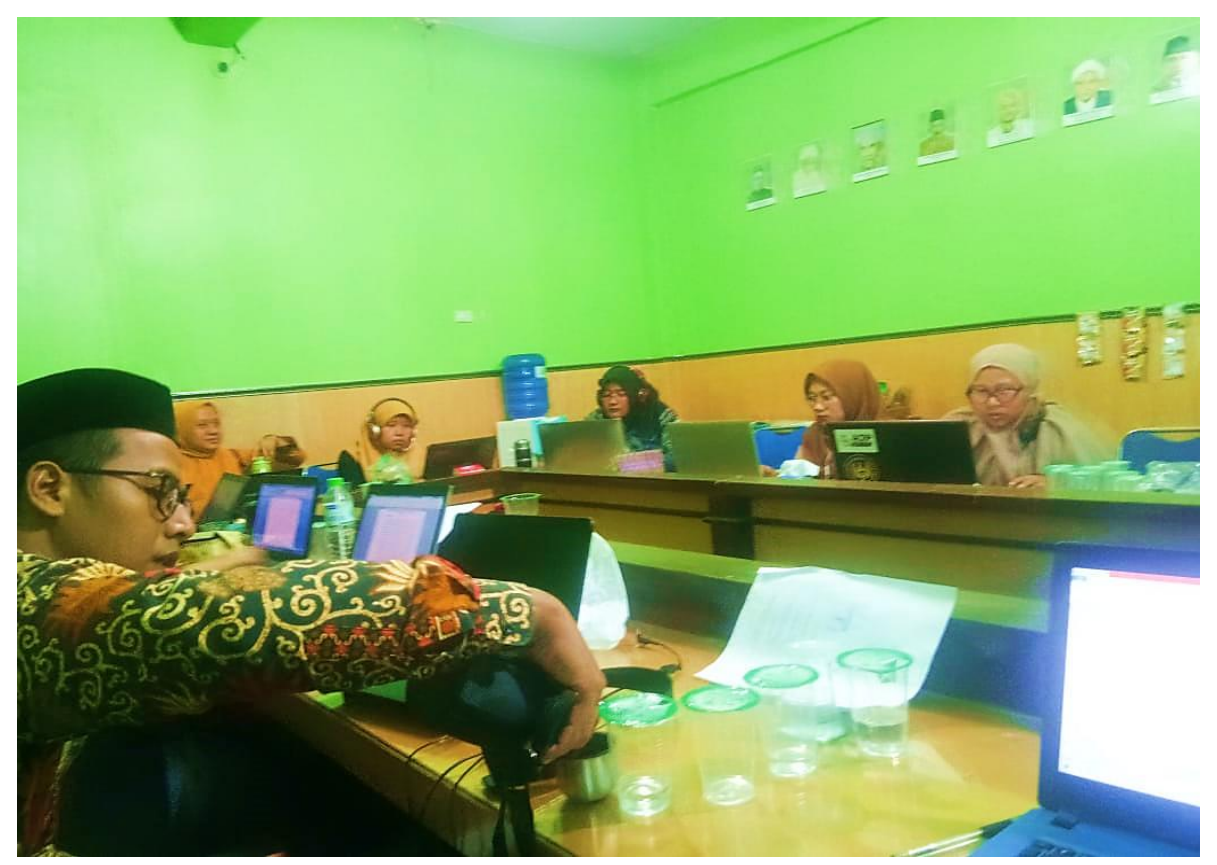

Gambar 1. Proses FGD oleh Tim PKM dan Dosen

3. Analisis strategi program

Tim melakukan FGD dengan tim dosen untuk menentukan kegiatan apa yang dapat dilakukan dalam pendampingan yaitu melakukan Workshop Kapasitas Kewirausahaan dan juga pelatihan seni kaligrafi yang dilakukan pada Tanggal 17-18 Februari 2020 yang dilakukan di halaman Pondok Pesantren Ma'arif Metro.

4. Ringkasan narasi program

Pada tahapan aksi program, peneliti membuat rancangan yang telah disepakati bersama para santri Pondok Pesantren Mahasiswa Ma'arif NU Kota Metro pada tahap FGD yaitu membuat pelatihan pembuatan karya seni kaligrafi dengan teknik prada. Melalui teknik ini, karya seni kaligrafi diawali dengan pembuatan pola pada media lukisan, pola yang telah dibuat kemudian dibentuk timbul menggunakan bahan silikon. Pewarnaan pola timbul yang telah dibuat dilakukan menggunakan kertas prada berwarna emas dan perak (Safron, 2018). 


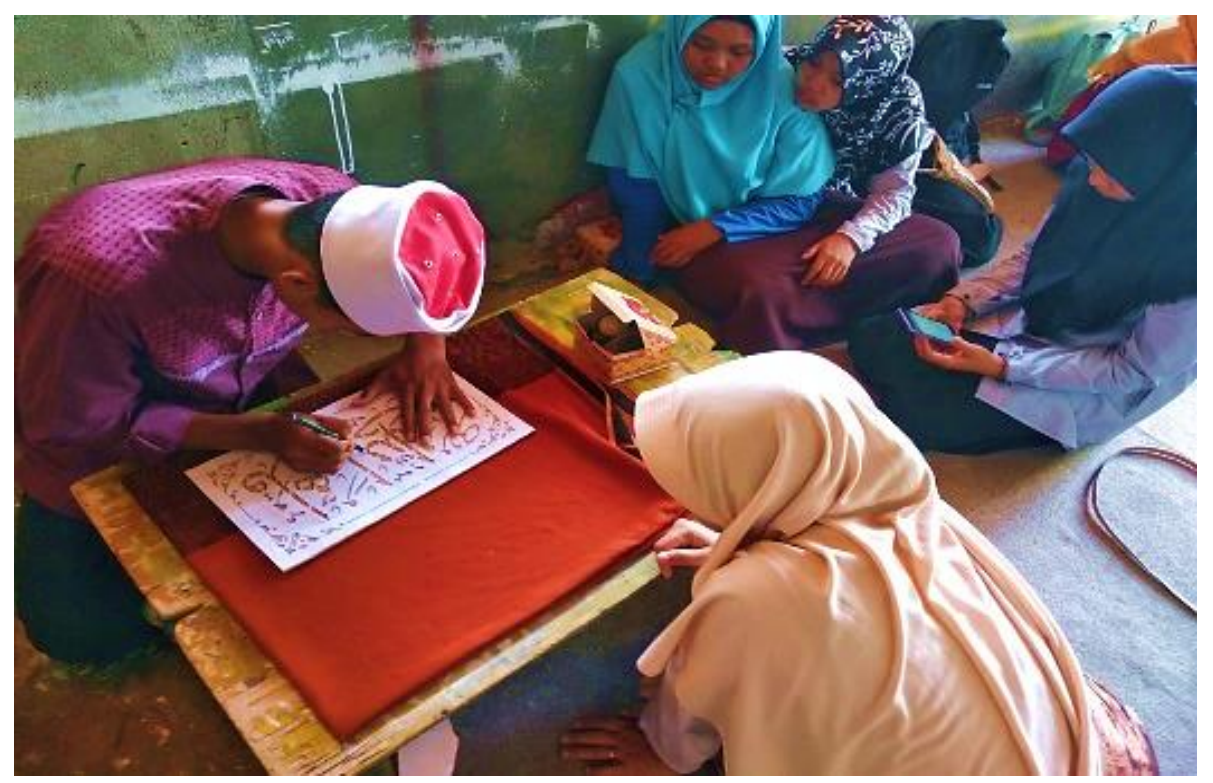

Gambar 2. Pelatihan seni kaligrafi oleh Bapak Ali Muhammad Wafa

Pada tahapan FGD telah dirumuskan bahwa pelatihan akan dilaksanakan pada tahap aksi yang telah disetujui bersama oleh santri Pondok Pesantren Mahasiswa Ma'arif NU Kota Metro. Hasil wawancara yang di lakukan kepada pengurus Pesantren Ma'arif NU Metro bahwa akan dilakukan pelatihan pada tanggal 17-18 Februari 2020 dengan materi tentang penguatan kapasitas kewirausahaan oleh Bapak Agus Setiawan, M.H.I selanjutnya pada tanggal 18 Februari 2020 materi tentang seni kaligrafi sekaligus praktik untuk kaligrafi yang diisi oleh Bapak Ali Muhammad Wafa.

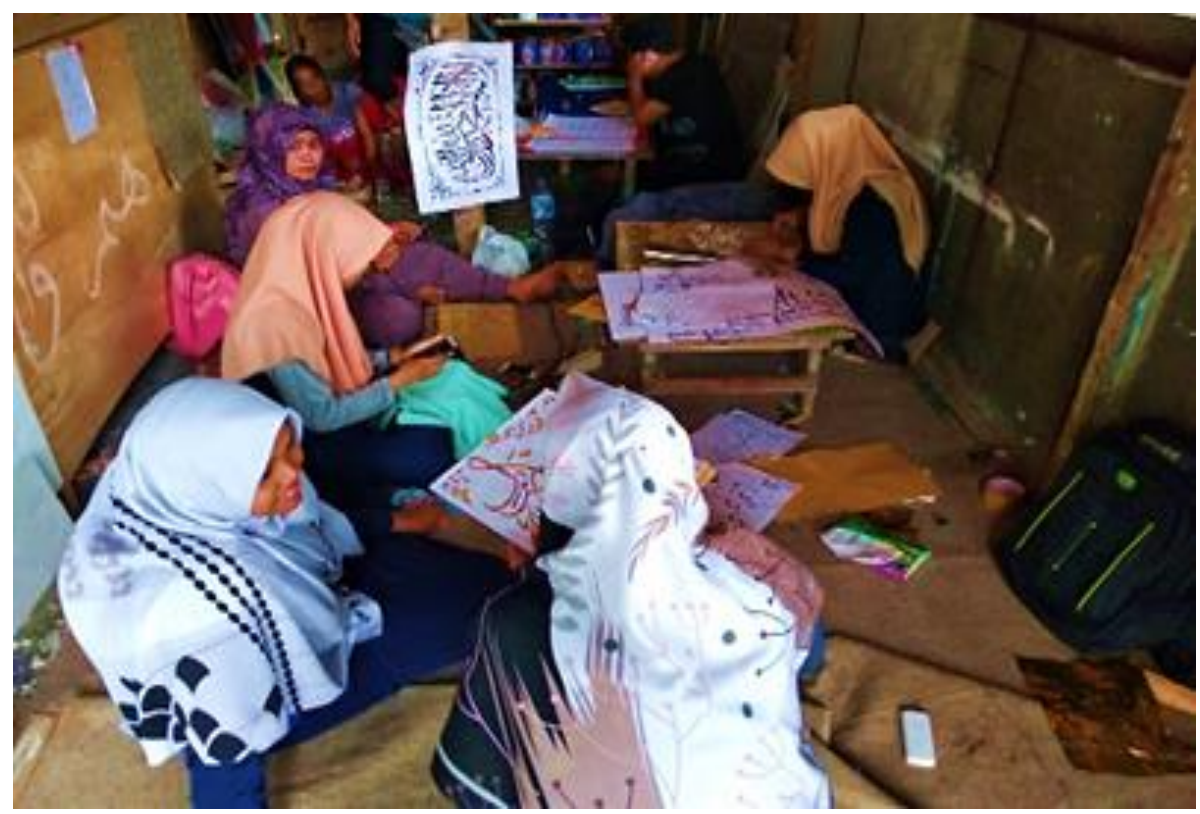

Gambar 3. Para santri praktik untuk membuat kaligrafi

5. Teknik monitoring dan evaluasi program

Proses monitoring akan terus dilakukan oleh peneliti agar proses santri Pondok Pesantren Mahasiswa Ma'arif NU Kota Metro terus berkelanjutan. 


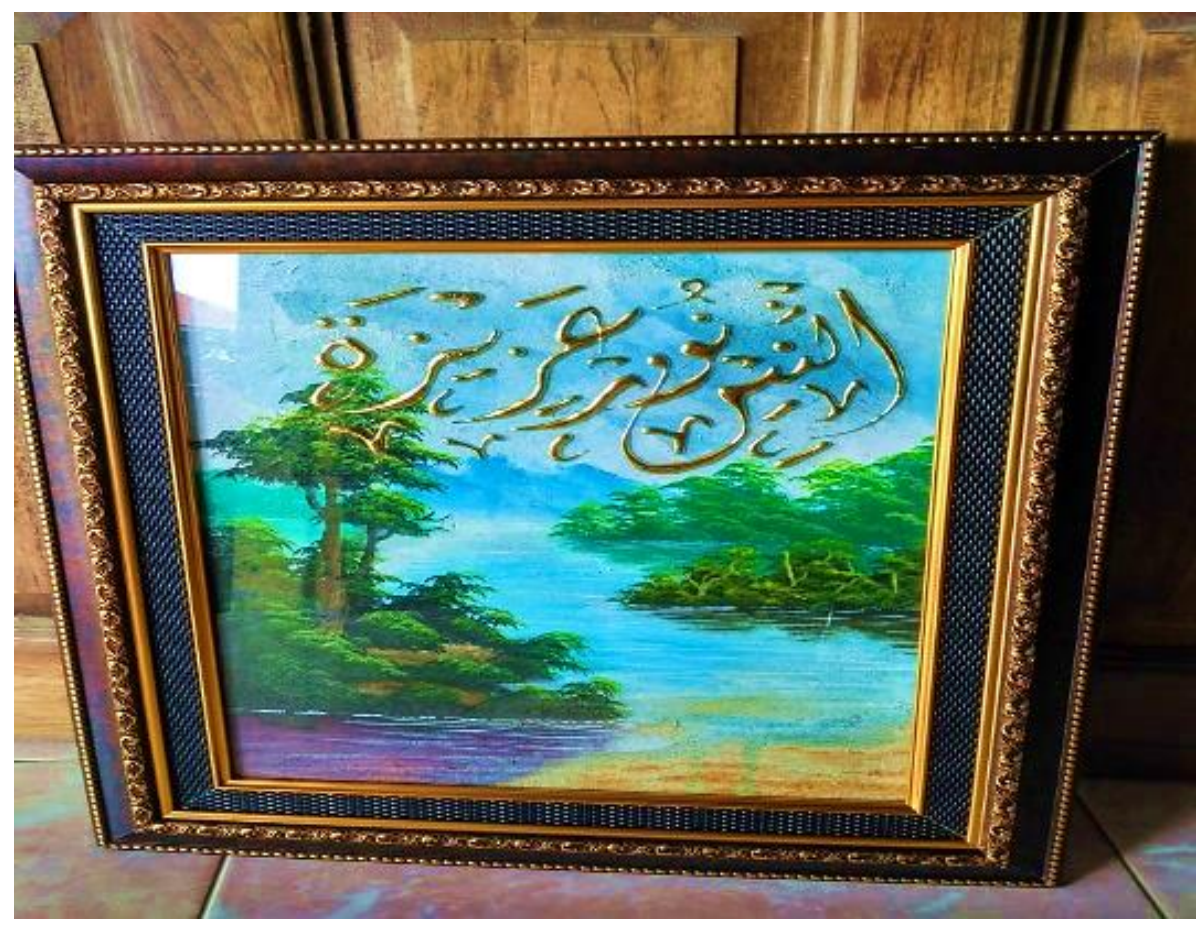

Gambar 4. Kaligrafi hasil karya mahasiswa yang siap di pasarkan

Dalam hal ini monitoring dilakukan setiap 3 bulan sekali untuk melihat bagaimana progress yang muncul pada subjek pengabdian, khususnya terkait tentang berwirausaha seni kaligrafi. Hasil monitoring dan evaluasi dari pendampingan yang dilakukan, santri terus melakukan pengembangan usaha kaligrafi yang dijalankan dengan keuntungan sepenuhnya untuk membiayai kebutuhan santri di pondok pesantren. Dari keuntungan tersebut, santri sudah tidak sepenuhnya bergantung dengan kiriman orang tua, hasil usaha kaligrafi yang dilakukan mampu memenuhi kebutuhan sendiri para santri yang berwirausaha. Hal ini sesuai dengan pendampingan yang dilakukan Komara et al. (2020), dimana kecakapan dan keterampilan yang dimiliki santri terbentuk atas inisiatif dan kemampuan inovatif sehingga menghantarkan para santri pada kemandirian. Melalui kewirausahaan dapat terpenuhi kebutuhan, sehingga para santri dapat terbebaskan dalam masalah perekonomian, para santri mampu memenuhi kebutuhan hidupnya sendiri dari hasil usahanya. Para santri juga dapat mengamalkan ilmu atau mengajarkan keterampilan yang mereka miliki kepada santri dan teman-teman mereka yang lain dengan tujuan meningkatkan pengetahuan dan keterampilan dalam bidang kewirausahaan.

\section{KESIMPULAN}

Kegiatan Program Pemberdayaan dan Pengembangan Kewirausahaan Pondok Pesantren Mahasiswa Ma'arif NU Kota Metro melalui Karya Seni Kaligrafi terlaksana dalam bentuk workshop dan pelatihan yang dihadiri oleh 70 santri. Program terlaksana melalui pendekatan $\mathrm{ABCD}$ dengan beberapa tahap antara lain penemuan apresiatif, analisis pengembangan aset, analisis strategi program, ringkasan narasi program serta teknik monitoring dan evaluasi program. Hasil pendampingan menunjukkan santri terus melakukan pengembangan usaha kaligrafi yang dijalankan dengan keuntungan sepenuhnya untuk membiayai kebutuhan santri di pondok pesantren. Dari keuntungan tersebut, santri sudah tidak sepenuhnya bergantung dengan kiriman orang tua, hasil usaha kaligrafi yang dilakukan mampu memenuhi kebutuhan sendiri para santri yang berwirausaha. 


\section{UCAPAN TERIMA KASIH}

Pendampingan ini didanai melalui bantuan pengabdian kepada masyarakat oleh Lembaga Publikasi, Penelitian, dan Pengabdian Kepada Masyarakat (LP3M) IAIMNU Kota Metro dengan Nomor 11/0136/IAIMNU/LPM/III/2021.

\section{REFERENSI}

Amrulloh, H., Mahmudah, M. 2020. Pembelajaran IPA SD/MI yang Menyenangkan. Malang: Pustaka Learning Center

Bilan, Y., Mishchuk, H., Roshchyk, I., Kmecova, I. 2020. An Analysis of Intellecutal Potential and its Impact on the Social and Economic Development of European Countries. Journal of Competitiveness. 12(1):22-38. https://doi.org/10.7441/joc.2020.01.02.

Dellyana, D., Sudrajad, O.Y. 2021. Capturing the Velocity of Sharia Economy Through an Islamic Boarding School's (Pesantren) B2B E-Commerce. In Handbook of Research on Innovation and Development of E-Commerce and E-Business in ASEAN. 457-484. https://doi.org/10.4018/978-1-7998-4984-1.ch023

Fatimah, S., Suib, M.S. 2019. Transformasi Sistem Pembayaran Pesantren Melalui E-Money Di Era Digital (Studi Pondok Pesantren Nurul Jadid). Jurnal Ekonomi dan Bisnis. 20(2):96-108. https:/ / doi.org/10.30659/ekobis.20.2.96-108

Graves, J.A., Quotah, E., Simmons, A. 2019. Islamic Calligraphy: Writing Toward the Light. Art Education. 72(2):14-19. https://doi.org/10.1080/00043125.2019.1559584

Haromain, H. 2013. Manajemen Pengembangan Sumber Daya Manusia Pondok Pesantren. Jurnal Pendidikan Humaniora. 1(2):136-149.

Komara, B.D., Setiawan, H.C.B., Kurniawan, A. 2020. Pemberdayaan Santri Melalui Kewirausahaan Dan Kemampuan Penguatan Keunggulan Produk Berbasis Pada Kearifan Lokal. Jurnal Riset Entrepreneurship. 3(2):15-22. https://doi.org/10.30587/jre.v3i2.1559

Ma`arif, M.A. 2019. Internalisasi Nilai Multikulutural Dalam Mengembangkan Sikap Toleransi (Studi Di Di Pesantren Mahasiswa Universitas Islam Malang). Nazhruna: Jurnal Pendidikan Islam. 2(1):164-189. https://doi.org/10.31538/nzh.v2i1.179

Nuryanta, N. 2008. Pengelolaan Sumber Daya Manusia (Tinjauan Aspek Rekrutmen Dan Seleksi). El-Tarbawi. 1(1):55-69. https://doi.org/10.20885/tarbawi.vol1.iss1.art5

Osborn, J.R. 2015. Narratives of Arabic Script: Calligraphic Design and Modern Spaces. Design and Culture. 1(3):289-306. https://doi.org/10.1080/17547075.2009.11643292

Safron, D. 2018. Penciptaan Kaligrafi Arab Teknik Timbul Dari Bahan Silikon. Skripsi. Medan: Universitas Negeri Medan

Sholikhan, M., Prasetyo, S.Y.J., Hartomo, K.D. 2019. Pemetaan Lokasi UMKM Kaligrafi Kabupaten Kudus Dengan Metode Location Based Service Sebagai Media Promosi Berbasis WebGIS. ICM Indonesian Journal of Computing and Modeling. 2(1): 8-16

Syafe'i, I. 2017. Pondok Pesantren: Lembaga Pendidikan Pembentukan Karakter. Al-Tadzkiyyah : Jurnal Pendidikan Islam. 8(1): 61-82. https://doi.org/10.24042/atjpi.v8i1.2097

Tursunbayeva, A. 2019. Human Resource Technology Disruptions and Their Implications for Human Resources Management in Healthcare Organizations. BMC Health Services Research. 19:268. https://doi.org/10.1186/s12913019-4068-3.

Zarnuji, A., Amrulloh, H., Azizah, I.N. 2018. Pengabdian Masyarakat Berbasis Riset: Pemanfaatan Sekam Padi Menjadi Kertas Sebagai Media Kaligrafi. Lampung Tengah: Wali Songo Sukajadi. 